\title{
FORMULATION AND EVALUATION OF SOMATOSTATIN ANALOGUE TABLETS
}

\section{ZOYA SHPRAKHa, ${ }^{\mathrm{a}}{ }^{*}$, OLGA ORLOVA ${ }^{\mathrm{a}}$, ELENA IGNATIEVAa ${ }^{\mathrm{a}}$, NATALYA OBOROTOVA ${ }^{\mathrm{a}}$, NATALYA BUNYATYAN}

aN. N. Blokhin National Medical Research Center of Oncology (N.N. Blokhin NMRCO), 24 Kashirskoye sh., Moscow, 115478, Russia, b. M. Sechenov First Moscow State Medical University (Sechenov University), 8-2 Trubetskaya st., Moscow, 119991, Russia Email: z.shprakh@ronc.ru

Received: 25 Fab 2019, Revised and Accepted: 10 May 2019

\section{ABSTRACT}

Objective: This study was undertaken with the aim of the formulation and evaluation of hypothalamic hormone somatostatin analogue tablets, which are intended for neuroendocrine tumours treatment.

Methods: Tablets were prepared by using the wet granulation method and evaluated for weight variation, resistance to crushing, friability, disintegration time, content and content uniformity. Stability tests have been performed.

Results: Characteristics of somatostatin analogue cyphetrylin powder have been investigated, and the wet granulation method has been chosen to prepare tablets. Technical pharmaceutical properties of formulations of different compositions and obtained tablets were estimated and the best formulation CF11 has been established with appropriate characteristics: disintegration time less than 15 min, resistance to crushing more than 30 $\mathrm{kg} \cdot \mathrm{m} \cdot \mathrm{s}^{-2}$, weight variation $<7.5 \%$, active substance content closed to the nominal quantity and consistent cyphetrylin distribution in the batch. Performed examinations showed cyphetrylin tablets stability in the long-term study.

Conclusion: Because of somatostatin analogue cyphetrylin powder properties tablets were prepared by the wet granulation method with starch, lactose, povidone, talc, microcrystalline cellulose, calcium stearate and magnesium stearate as excipients. The best formulation including povidone has characteristics corresponding to requirements of European Pharmacopoeia (PhEur) and State Pharmacopoeia of the Russian Federation $(\mathrm{PhRu})$. Examination of cyphetrylin tablets showed its quality and stability within the time of observation-12 mo.

Keywords: Somatostatin analogue, Cyphetrylin, Tablets, Formulations, Pharmaceutical technical characteristics, Content and content uniformity, Stability studies

(C) 2019 The Authors. Published by Innovare Academic Sciences Pvt Ltd. This is an open-access article under the CC BY license (http://creativecommons.org/licenses/by/4.0/) DOI: http://dx.doi.org/10.22159/ijap.2019v11i4.32795

\section{INTRODUCTION}

Neuroendocrine Tumours (NET) are rare human tumour arising from the cells of the diffuse neuroendocrine system located in various organs and tissues of the human body (gastrointestinal tract, lungs, pituitary gland, etc.). This type of tumours is characterized by the presence of secondary symptoms caused by metabolically active substances hyperproduction and secretion $[1,2]$.

Biotherapy with Somatostatin Analogues (SSA) has a proven effect in the treatment of clinical syndromes (carcinoid syndrome, hypoglycemia syndrome, Zollinger-Ellison syndrome, etc.). The drugs in this group (most widely used three SSA are as follows: octreotide, lanreotide and pasireotide) suppress clinical symptoms and reduce the level of biochemical tumour markers and also have useful anti-proliferative activity [3, 4].

Several SSAs has been synthesised in N.N. Blokhin NMRCO, including cytotoxic SSAs, and their antitumor effect has been studied in the experiments in vitro and in vivo. According to the results of the preliminary investigations, a hypothalamic hormone somatostatin analogue cyphetrylin has been selected for a preclinical study. Cyphetrylin is pentapeptide (Boc-Cys(Thp)-Phe-D-Trp-Lys(Z)-ThrOMe) with noncyclic structure [5].

Usually, parenteral way of administration is used for peptide drug administration because of their enzymatic instability $[6,7]$. But cyphetrylin is insoluble in water, and it is metabolically stable in the gastric fluid because of reactive groups blocking. The specific studies of cyphetrylin in vivo showed its high antitumor efficiency on animal's experimental tumours and xenografts by oral administration $[8,9]$.

The objective of the present study was to create hypothalamic hormone analogue cyphetrylin dosage form composition and preparation method and to evaluate obtained pharmaceutical by different parameters according to requirements of current editions of PhEur and $\mathrm{PhRu}[10,11]$.

This investigation is the first attempt to obtain a dosage form of new original somatostatin analogue for oral administration.

\section{MATERIALS AND METHODS}

\section{Materials}

Cyphetrylin substance was obtained from chemical synthesis laboratory of N.N. Blokhin NMRCO, potato starch, lactose (because cyphetrylin isn't sensitive to moisture we used lactose monohydrate [12]), povidone, talc, microcrystalline cellulose, calcium stearate and magnesium stearate were purchased from different suppliers and conformed to PhEur requirements. All other used chemicals and solvents were of analytical grade.

Methods

\section{Bulk density}

$2 \mathrm{~g}$ of cyphetrylin powder or cyphetrylin granulate previously lightly shaken to break any agglomerates formed was introduced into a 10 $\mathrm{ml}$ measuring cylinder. After the initial volume was observed, then calculate the bulk density using the following formula $[10,11]$.

$$
\text { Bulk Density }=\frac{\text { Weight of the powder }}{\text { Bulk volume }}
$$

\section{Angle of repose}

The angle of repose of cyphetrylin granulate was determined by the fixed funnel method. The accurately weighed powder was taken in a funnel. The height of the funnel was adjusted in such a way that the tip of the funnel just touched the apex of the heap of the powder. The powder was allowed to flow through the funnel freely onto the surface. The diameter of the powder cone was measured, and the angle of repose was calculated using the following equation $[10,11]$.

$$
\tan \theta=\frac{\mathrm{h}}{\mathrm{r}}
$$

Where, $\theta=$ angle of repose,

$\mathrm{h}=$ height of the pile 
$r=$ radius of the pile base

\section{Weight variation test}

To study weight variation 20 tablets of each formulation were weighed using an electronic analytical balance. The average weight was calculated, then individual tablet weight was compared with average weight $[10,11]$.

\section{Disintegration time}

The examination of disintegration time was carried on randomly selected six tablets of each formulation without disks. The purified water was used as a disintegration medium and temperature was maintained at $37 \pm 0.5{ }^{\circ} \mathrm{C}$. The average disintegration time of six tablets was noted down for calculation $[10,11]$.

\section{Resistance to crushing and friability}

The test of resistance to crushing was measured on tester consists of two jaws facing each other, one of which moves towards the other. The tester is calibrated with the precision of $\mathrm{kg} \cdot \mathrm{m} \cdot \mathrm{s}^{-2}$. The measurement is carried out on ten tablets $[10,11]$.

The friability test was performed by using tablet friability tester Erweka (Germany). Ten tablets were accurately weighed and placed in the tester and operated for 100 revolutions. The tablets were dedusted and reweighed, and friability was calculated using the following equation.

$$
\text { Friability }=\frac{\text { Initial weight }- \text { Final weight }}{\text { Initial weight }} \times 100
$$

\section{An analytical method for cyphetrylin assay in tablets}

The analytical method for cyphetrylin assay in tablets has been created and validated [13, 14]. Cyphetrylin content under formulation developed was estimated with Carry 100 UV-Visible spectrophotometer (USA). The specially synthesised cyphetrylin substance of $99.0 \%$ of the active ingredient was used as a standard sample.

About $100 \mathrm{mg}$ of cyphetrylin rubbed tablets were dissolved in $50 \mathrm{ml}$ of ethanol $(0.12 \mathrm{mg} / \mathrm{ml})$ and filtered via Millipore with pore size $0.45 \mu \mathrm{m}$. The absorbance of this solution was measured at the maximum wavelength of cyphetrylin of $282 \pm 2 \mathrm{~nm}$. The absorbance of the cyphetrylin standard spirituous solution of the same concentration was measured in parallel. Cyphetrylin quantity calculation was carried out by a formula taking into consideration dilutions of all solutions and cyphetrylin content in substance.

\section{Uniformity of drug content}

The determination was performed for ten tablets separately by UVspectrophotometry method described for assay test. $25 \mathrm{ml}$ of $95 \%$ ethyl alcohol were added to each tablet and shook intensively during 8-10 min. The liquid was filtered, and the drug content was determined after appropriate dilution with $95 \%$ ethyl alcohol.

\section{RESULTS AND DISCUSSION}

\section{Characterization of powder}

The general technological properties of cyphetrylin powder mentioned in table 1.

Table 1: Technological characteristics of cyphetrylin powder

\begin{tabular}{llll}
\hline No & Technological characteristics & Results & \\
\hline 1. & Particle size & $0.1 \mathrm{~mm}$ and less-86 \% & $0.1-0.25 \mathrm{~mm}-4 \%$ \\
2. & Particles form & Circular & Needle-like crystal \\
3. & Wettability & Doesn't get wet & \\
4. & Bulk density* & $0.09 \pm 0.01 \mathrm{~g} / \mathrm{ml}$ & Spherical conglomerate \\
5. & Flowability* & $0.1 \pm 0.02 \mathrm{~g} / \mathrm{s}$ & \\
\hline
\end{tabular}

*All values are expressed as mean \pm SD, $n=6$

It is visible that cyphetrylin powder is polydisperse-its particles are of different form and size (table 1). The fraction with a particle size less $0.25 \mathrm{~mm}$ is more than half, that way it is necessary to use excipients to increase particle size and mass and flowability. The substance doesn't get wet, and it means that it is required to include appropriate excipients to control tablets disintegration.

To improve cyphetrylin powder properties (at first flowability) we decided to use wet granulation. Because cyphetrylin is insoluble in water, but the mixture of cyphetrylin and excipients is well wettable by water, $5 \%$ starch paste and $1 \%$ and $2 \%$ povidone solution were tested as granulation agents.
To prepare granulate of cyphetrylin the mixtures of active substance and excipients (for 20 tablets) were wetted by starch paste or $1 \%$ or $2 \%$ povidone solution and dried to complete drying out. When dried, granulates were passed through a mesh sieve \#710, powder mixture (magnesium stearate, talc and starch) was added to the blend and compressed into tablets on eccentric tablet press Erweka (Germany) using $6 \mathrm{~mm}$ punch.

Formulations with the different correlation of ingredients have been prepared (table 2). The cyphetrylin dose in all tablets was $6 \mathrm{mg}$. As it was shown by a series of biological experiments in vivo, it is required cyphetrylin quantity to demonstrate antitumor efficiency and safety.

Table 2: Composition cyphetrylin formulation for tablets

\begin{tabular}{|c|c|c|c|c|c|c|c|c|c|c|c|}
\hline \multirow[t]{2}{*}{ Ingredients, mg/tab } & \multicolumn{11}{|c|}{ Formulation code } \\
\hline & CF1 & CF2 & CF3 & CF4 & CF5 & CF6 & CF7 & CF8 & CF9 & CF10 & CF11 \\
\hline Cyphetrylin & 6 & 6 & 6 & 6 & 6 & 6 & 6 & 6 & 6 & 6 & 6 \\
\hline Lactose & 50 & 30 & 35 & 45 & 50 & 50 & 55 & 60 & 60 & 55 & 55 \\
\hline Microcrystalline cellulose & 25 & 35 & 15 & 20 & 15 & 10 & 10 & 10 & 5 & 10 & 5 \\
\hline Starch & 10 & 20 & 35 & 25 & 25 & 30 & 25 & 25 & 25 & 20 & 25 \\
\hline Povidone & & & & & & & & & & & 5 \\
\hline Powder blend (magnesium stearate, talc and starch) & 10 & 10 & 10 & 10 & 10 & 10 & 10 & 10 & 10 & 10 & 10 \\
\hline
\end{tabular}

CF-cyphetrylin formulation

All granulates (table 2, formulations 1-7) possess sufficient flow properties and good packing ability. The best with necessary flowability $(3.0 \mathrm{~g} / \mathrm{s})$, bulk density $(0.15 \mathrm{~g} / \mathrm{ml})$ and angle of repose $\left(40.8 \pm 1.1^{\circ}\right)$ was mixture №7. But resistance to crushing of tablets obtained from this formulation was insufficient (table 4) and didn't meet to the recommendations of PhRu [11], so we continued to create tablet formulation (table 2, formulations 811). 
The flow properties of the final blend were tested by measuring bulk density, flowability and the angle of repose and they were found to be the best for CF11 formulations. As is seen from table 3, povidone inclusion into formulation led not only to sufficient flow characteristics but to the optimal correlation between resistance to crushing and disintegration.
Experimental tablets were prepared by tablet press Erweka (Germany). All the prepared formulations were evaluated for different physicochemical properties for physical parameters: appearance, resistance to crushing, friability, disintegration, average weight, weight variation, and results are presented in table 4 .

Table 3: Characteristics of formulation CF11 and obtained tablets

\begin{tabular}{|c|c|c|c|c|}
\hline Formulation (CF11) & & & Tablets (CF11)* & \\
\hline Bulk density* $(\mathrm{g} / \mathrm{ml})$ & Flowability* (g/s) & Angle of repose ${ }^{*}\left({ }^{\circ}\right)$ & Disintegration ${ }^{*}$ (min) & Resistance to crushing\# $\left(\mathrm{kg} \cdot \mathrm{m} \cdot \mathrm{s}^{-2}\right)$ \\
\hline $0.49 \pm 0.01$ & $6.43 \pm 0.02$ & $40.8 \pm 1.1$ & $9.3 \pm 1.2$ & $38.3 \pm 2.3$ \\
\hline
\end{tabular}

${ }^{*}$ All values are expressed as mean $\pm \mathrm{SD},{ }^{*} \mathrm{n}=6, \# \mathrm{n}=10$

Appearance and test of weight variation may be the most straightforward indicators of technology compliance. The appearance of prepared cyphetrylin tablets was high-quality (white, straight, circular, $6 \mathrm{~mm}$ diameter, biconvex tablets) except formulations CF2, CF3 and CF9, which surfaces were off-white and slightly marbled (of unequal colour).

The examination of weight variation showed that average weight of cyphetrylin tablets of all compositions was within the range of calculated mass $\pm 10 \%$, and maximum weight variation was $7.29 \%$, which was in PhEur and PhRu limits of $\pm 7.5 \%$.

Tablet mechanical characteristics provide their stability within the manufacture and useful quality. Tablets must pass these points, and tablet defects are nonaccepted.
The results of prepared tablets in the test of resistance to crushing were in the range of 7.32 to $38.32 \mathrm{~kg} \cdot \mathrm{m} \cdot \mathrm{s}^{-2}$ but only composition CF11 resistance to crushing $\left(38.32 \pm 0.12 \mathrm{~kg} \cdot \mathrm{m} \cdot \mathrm{s}^{-2}\right)$ corresponded to $\mathrm{PhRu}$ recommendations-minimal value has to be not less than 30 $\mathrm{kg} \cdot \mathrm{m} \cdot \mathrm{s}^{-2}$ for tablets of this diameter. At the same time, disintegration test for CF11 composition was successful, and tablets passed the test (less than $15 \mathrm{~min}$ ).

The friability test for compositions CF2, CF3, CF6 and CF9 was more than the limit ( $1 \%$ ), but other compositions friability was less what is illustrative of tablets good mechanical resistance.

All formulations passed the disintegration test by taking time (not more than $15 \mathrm{~min}$ ). Formulations CF4, CF6 and CF10 have shown disintegration time near to the limit, but formulations CF2 and CF9 had disintegration time lower than ideal.

Table 4: Pharmaceutical technical characteristics of cyphetrylin tablets

\begin{tabular}{|c|c|c|c|c|c|c|}
\hline $\begin{array}{l}\text { Formulation } \\
\text { code }\end{array}$ & Appearance & $\begin{array}{l}\text { Resistance to } \\
\text { crushing\# }\left(\mathrm{kg} \cdot \mathrm{m} \cdot \mathrm{s}^{-2}\right)\end{array}$ & $\begin{array}{l}\text { Friability* } \\
\text { (\%) }\end{array}$ & $\begin{array}{l}\text { Disinteg } \\
\text { ration (min) }\end{array}$ & $\begin{array}{l}\text { Average weight } \\
\text { (mg)* }\end{array}$ & $\begin{array}{l}\text { Weight } \\
\text { variation }(\%)^{*}\end{array}$ \\
\hline CF1 & White straight tablets & $10.79 \pm 0.28$ & 0.91 & 8 & $98.62 \pm 7.28$ & 5.48 \\
\hline $\mathrm{CF} 2$ & $\begin{array}{l}\text { Off-white straight tablets, } \\
\text { unequal colored }\end{array}$ & $7.32 \pm 0.43$ & 1.20 & 3 & $107.89 \pm 9.31$ & 7.12 \\
\hline CF3 & $\begin{array}{l}\text { Off-white straight tablets, } \\
\text { unequal colored }\end{array}$ & $8.99 \pm 0.37$ & 1.15 & 6 & $103.46 \pm 6.44$ & 6.49 \\
\hline CF4 & White straight tablets & $17.76 \pm 0.11$ & 0.83 & 14 & $94.67 \pm 8.89$ & 6.32 \\
\hline CF5 & White straight tablets & $14.40 \pm 0.29$ & 0.99 & 9 & $102.38 \pm 7.96$ & 5.67 \\
\hline CF6 & White straight tablets & $15.04 \pm 0.59$ & 1.08 & 11 & $100.31 \pm 4.96$ & 7.29 \\
\hline CF7 & White straight tablets & $19.60 \pm 0.15$ & 0.98 & 9 & $106.99 \pm 10.16$ & 4.67 \\
\hline CF8 & White straight tablets & $14.76 \pm 0.18$ & 0.94 & 8 & $112.43 \pm 7.92$ & 6.39 \\
\hline CF9 & $\begin{array}{l}\text { Off-white straight tablets, } \\
\text { unequal colored }\end{array}$ & $7.50 \pm 0.64$ & 1.12 & 3 & $101.49 \pm 9.42$ & 5.08 \\
\hline CF10 & White straight tablets & $24.81 \pm 0.21$ & 0.96 & 12 & $98.32 \pm 6.29$ & 6.75 \\
\hline CF11 & White straight tablets & $38.32 \pm 0.12$ & 0.93 & 9,3 & $102.39 \pm 6.71$ & 5.86 \\
\hline
\end{tabular}

*All values are expressed as mean $\pm S D, n=6,{ }^{*} n=20, \# n=10$

As is seen from table 4 above, investigations revealed that CF11 formulation with povidone addition has an optimal correlation of mechanical properties and disintegration.

\section{Assay and content uniformity}

Because cyphetrylin dose in the tablet is $6 \mathrm{mg}$ (less than $6 \%$ ), the quantity of the active substance in each tablet is the most critical parameter. And according to the requirement of PhEur and PhRu, it is necessary to determine the uniformity of drug content. The test was carried out on ten tablets by direct estimation of each unit. The conditions of determination were equal to the assay test.

Results of quantitative determinations of two cyphetrylin tablets batches are presented in table 5. Each point is an average of six determinations.

Table 5: Results of content estimations for cyphetrylin tablets 6 mg

\begin{tabular}{lll}
\hline Batch & Cyphetrylin content (mg) & Content uniformity \\
\hline 010317 & $\bar{X}=6.0$ & $\mathrm{n}=10 \mathrm{k}(\mathrm{f}, \mathrm{P})=2.4$ \\
& $\mathrm{~S}=0.1072 \Delta \mathrm{x}=0.099$ & $\mathrm{~S}=3.8453$ \\
$\mathrm{t}(\mathrm{p}, \mathrm{f})_{\text {calc }}=0.459$ & $\bar{X}=96.1<98.5$ \\
$\bar{\varepsilon}=1.66 \%$ & $\mathrm{M}($ Reference value) $=98.5$ \\
& & AV(Acceptance value), $\%=11.6<15.0$ \\
041117 & $\bar{X}=5.9$ & $\mathrm{n}=10 \mathrm{k}(\mathrm{f}, \mathrm{P})=2.4$ \\
& $\mathrm{~S}=0.1018 \Delta \mathrm{x}=0.093$ & $\mathrm{~S}=4.6932$ \\
& $\mathrm{t}(\mathrm{p}, \mathrm{f})$ calc $=0.260$ & $\bar{X}=95.2<98.5$ \\
& $\bar{\varepsilon}=1.57 \%$ & M (Reference value) $=98.5$ \\
& & AV(Acceptance value) $\%=11.3<15.0$ \\
\hline
\end{tabular}

As it is seen from table 5, tests have shown the consistency of active substance content in the tablet and cyphetrylin distribution in the batch. 
Cyphetrylin tablets stability studies were performed to evaluate chosen formulation physical and chemical attributes in a long-term study at 25
${ }^{\circ} \mathrm{C} / 60 \%$ RH. The table 6 data show that all characteristics of the preparation are stable during the time of storage $(12 \mathrm{mo})$.

Table 6: Results of cyphetrylin tablets 6 mg stability tests

\begin{tabular}{|c|c|c|c|}
\hline \multirow[t]{3}{*}{ Batch № } & \multirow[t]{3}{*}{ Time } & Disintegration (min) & Content (mg) \\
\hline & & \multicolumn{2}{|l|}{ Limits by specification } \\
\hline & & Not more than 15 & From 5.4 to 6.6 \\
\hline \multirow[t]{5}{*}{010317} & 0 & 8 & 6.4 \\
\hline & $3 \mathrm{mo}$ & 8 & 6.5 \\
\hline & 6 moths & 7 & 6.3 \\
\hline & $9 \mathrm{mo}$ & 8 & 6.4 \\
\hline & $12 \mathrm{mo}$ & 8 & 6.3 \\
\hline \multirow[t]{5}{*}{021117} & 0 & 9 & 6.0 \\
\hline & $3 \mathrm{mo}$ & 8 & 6.0 \\
\hline & 6 moths & 8 & 5.9 \\
\hline & $9 \mathrm{mo}$ & 9 & 5.9 \\
\hline & $12 \mathrm{mo}$ & 8 & 5.8 \\
\hline \multirow[t]{5}{*}{031117} & 0 & 7 & 5.5 \\
\hline & $3 \mathrm{mo}$ & 7 & 5.5 \\
\hline & 6 moths & 8 & 5.5 \\
\hline & 9 mo & 7 & 5.6 \\
\hline & $12 \mathrm{mo}$ & 7 & 5.4 \\
\hline
\end{tabular}

\section{CONCLUSION}

Because of somatostatin analogue cyphetrylin powder characteristics, tablets were prepared by wet granulation method with starch, lactose, povidone, talc, microcrystalline cellulose, calcium stearate and magnesium stearate as excipients.

The best formulation including povidone has characteristics corresponding to the requirements of European Pharmacopoeia and State Pharmacopoeia of the Russian Federation: disintegration time less than $15 \mathrm{~min}$, resistance to crushing more than $30 \mathrm{~kg} \cdot \mathrm{m} \cdot \mathrm{s}^{-2}$, weight variation $<7.5 \%$, active substance content closed to the nominal quantity and consistent cyphetrylin distribution in the batch. Performed examinations showed cyphetrylin tablets stability in a longterm study.

\section{ACKNOWLEDGMENT}

This work was funded by Russian Ministry of Industry and Trade (Grant Number 11411.0008700.13.082).

\section{AUTHORS CONTRIBUTIONS}

All the author have contributed equally

\section{CONFLICT OF INTERESTS}

Declared none

\section{REFERENCES}

1. Dasari A, Shen C, Halperin DM, Zhao B, Zhou S, Xu Y, et al. Trends in the incidence, prevalence, and survival outcomes in patients with neuroendocrine tumors in the United States. JAMA Oncol 2017;3:1335-42.

2. Vinik AI, Chaya C. Clinical presentation and diagnosis of neuroendocrine tumors. Hematol Oncol Clin North Am 2016;1:21-48

3. Yao JC, Lagunes DR, Kulke MH. Targeted therapies in neuroendocrine tumors (NET): clinical trial challenges and lessons learned. Oncologist 2013;5:525-32.
4. Faggiano A, Lo Calzo F, Pizza G, Modica R, Colao A. The safety of available treatments options for neuroendocrine tumors. Expert Opin Drug Saf 2017;20:1-13.

5. Shprakh ZS, Yartseva IV, Ignateva EV, Smirnova AP, Sushinina LP, Ustinkina SV, et al. Synthesis and chemico-pharmaceutical characteristics of somatostatin analog with antitumor activity. Pharm Chem J 2014;3:159-62.

6. Mohammed GK, Obaidat RM, Assaf S, Khanfar M, Al-taani B. Formulations and technologies in growth hormone delivery. Int J Pharm Pharm Sci 2017;7:1-12.

7. Preet P. Peptides: a new therapeutic approach. Int J Curr Pharm Res 2018;2:29-34.

8. Sanarova EV, Lantsova AV, Mikhaevich EI, Shprakh ZS, Smirnova LI, Yavorskaya NP, et al. The prospect of the creation of a dosage form of domestic analogue of hypothalamic hormone somatostatin in the treatment of hormone-dependent tumors. Russ J Biopharm 2016;2:14-9.

9. Konyaeva OI, Kulbachevskaya NYu, Ermakova NP, Chaley VA, Merkulova IB, Abramova TV, et al. Pre-clinical toxicological study of analogue of the hypothalamic hormone. Russ J Biother 2018;2:63-70.

10. European Pharmacopoeia 9.0. Strasbourg: Council of Europe; 2017.

11. State Pharmacopoeia of the Russian Federation. $14^{\text {th }}$ ed Moscow: The Ministry of Health of the Russian Federation; 2018.

12. Tadwee I, Shahi S, Zaheer Z. Preformulation studies using lactose in the development of solid oral dosage form: a graphical representation using SeDeM method. Int J Curr Pharm Res 2017;5:168-72.

13. Lotfy HM, Saleh SS. Recent development in ultraviolet spectrophotometry through the last decade (2006-2016): a review. Int J Pharm Pharm Sci 2016,1:40-56.

14. Shprakh ZS, Ignatieva EV, Yartseva IV, Dmitricheva NA, Smirnova LI. Development and validation of cyphetrylin assay in tablets. Russ J Biother 2016;3:55-61. 